\title{
Linear endosonographic appearance of esophageal intramural pseudodiverticulosis
}

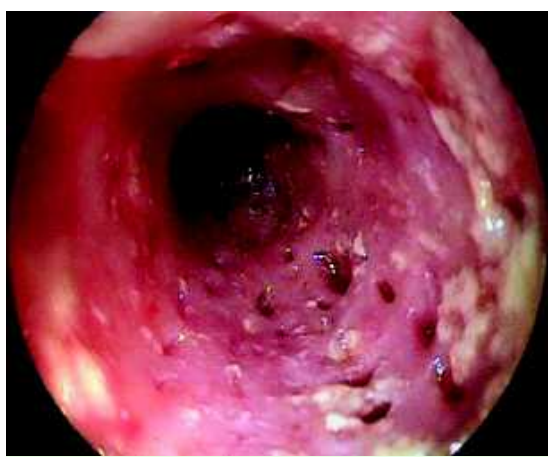

Fig. 1 Endoscopic view showing inflamed esophageal mucosa with adherent whitish plaques. Multiple small diverticular orifices were noted throughout the esophageal wall.

A 72-year-old lady presented for evaluation of dysphagia and endoscopic ultrasound (EUS) staging of lung cancer. Upper endoscopy showed a short-segment, nontraversable stricture at the upper third of the esophagus. Examination after balloon dilation revealed inflamed mucosa with adherent whitish plaques, and multiple tiny diverticular orifices throughout the esophagus ( $\bullet$ Fig. 1).

Endosonographic examination using a linear echoendoscope (EG-3830; Pentax Corp., Tokyo, Japan) was performed for assessment of the esophageal lesion and staging of lung cancer. A thickened mucosa and submucosa with multiple acoustic air reflections due to gas collection inside the diverticula was shown ( $\bullet$ Fig. 2, $\bullet$ Video 1 ).

The muscularis propria was intact. Mucosal biopsy confirmed chronic inflammation and Candida infection. The symptoms resolved with endoscopic dilation and antifungal treatment. The patient subsequently underwent an uneventful operation for squamous carcinoma of the right lung.

\section{Video 1}

Endoscopy showed multiple diverticular orifices throughout the esophagus, suggestive of esophageal intramural pseudodiverticulosis.

Linear endoscopic ultrasound confirmed this diagnosis by demonstrating typical features of a thickened mucosa and submucosa, intact muscularis propria, and multiple acoustic reflections in the esophageal wall.

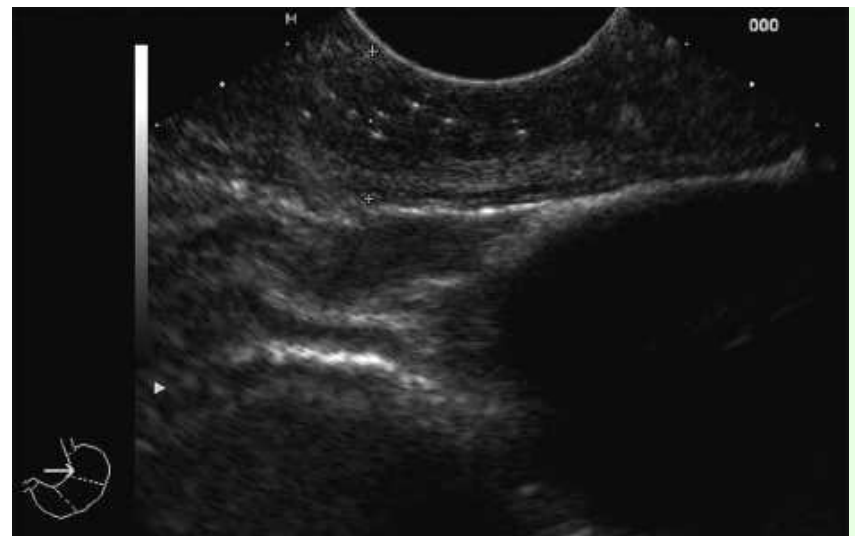

Fig. 2 Linear endoscopic ultrasound showing a thickened mucosa and submucosa with multiple acoustic reflections due to gas pockets in the diverticula. The muscle layer was intact.

Esophageal intramural pseudodiverticulosis (EIPD) is a rare benign condition of the esophagus first described by Mendl et al. in 1960 [1]. Since then, only 250 cases have been reported [2]. The condition is characterized by multiple saccular diverticula which histologically correspond to dilated secretory ducts of submucosal mucous gland $[2,3]$. These diverticula arise in a thickened mucosa and submucosa, whereas the underlying muscle layer remains intact. With the capability to evaluate the esophageal wall layers clearly, radial scanning EUS was found to be helpful in establishing the correct diagnosis of EIPD [4,5]. It demonstrated circumferential hypoechoic thickening of mucosa and submucosa, with a normal muscular layer. Multiple acoustic reflections due to gas pockets entrapped in the diverticula can be noted in the esophageal wall.

Our case illustrates that linear EUS can provide an equally good assessment for EIPD. In addition, the benefit of sampling suspicious periesophageal lymph nodes to exclude other etiologies is provided with the linear instrument. To our knowledge, this is the first reported linear EUS appearance of EIPD.

Endoscopy_UCTN_Code_CCL_1AB_2AC_3AF

\section{K.-H. Lok, P. Vilmann}

Department of Surgical Gastroenterology, Gentofte University Hospital, Hellerup,

Denmark

\section{References}

1 Mendl K, McKay JM, Tanner CH. Intramural diverticulosis of the oesophagus and Rokitanski-Aschoff sinuses in the gallbladder. Br J Radiol 1960; 33: 496-501

2 VanLaer $W$, Urbain D, Reynaert $H$. Esophageal intramural pseudodiverticulosis. Clin Gastroenterol Hepatol 2007; 5(12): A22

3 Herter B, Dittler HJ, Wuttge-Hannig A, Siewert JR. Intramural pseudodiverticulosis of the esophagus: a case series. Endoscopy 1997; 29: 109-113

4 Devereaux CE, Savides TJ. EUS appearance of esophageal pseudodiverticulosis. Gastrointest Endosc 2000; 51: 228-231

5 Yoshimoto T, Suzuki K, Yazumi S et al. Esophageal intramural pseudodiverticulosis. Gastrointest Endosc 2004; 59: 691 - 692

\section{Bibliography}

DOI $10.1055 / \mathrm{s}-2008-1077686$

Endoscopy 2008; 40: E251

(c) Georg Thieme Verlag KG Stuttgart · New York . ISSN 0013-726X

\section{Corresponding author}

\section{K.-H. Lok, MD}

Department of Surgical Gastroenterology D,

Gentofte University Hospital

Niels Andersensvej 65

2900 Hellerup

Denmark

Fax: 45-39777629

lokkaho@netvigator.com 